\title{
A PART-METRIC VARIANT OF NEWTON'S INEQUALITIES
}

\author{
Kenneth S. Berenhaut and Austin H. Jones
}

Abstract. This note gives a part-metric variant of Newton's inequalities. A particular case proved useful recently in the study of difference equations involving ratios of elementary symmetric polynomials.

Mathematics subject classification (2010): 26D20, $26 \mathrm{C} 05$.

Keywords and phrases: Newton's inequalities, symmetric functions, elementary symmetric polynomials, part-metric, difference equations.

\section{Introduction}

\section{REFERENCES}

[1] K. S. Berenhaut, J. D. Foley and S. Stevic. The global attractivity of the rational difference equation $y_{n}=1+\frac{y_{n-k}}{y_{n-m}}$. Proc. Amer. Math. Soc. 135 (2007), no. 4, 1133-1140.

[2] K. S. Berenhaut, J. D. Foley and S. Stevic. The global attractivity of the rational difference equation $y_{n}=\frac{y_{n-k}+y_{n-m}}{1+y_{n-k} y_{n-m}}$. Appl. Math. Lett. 20 (2007), 54-58.

[3] K. S. BerenhaUt AND A. H. Jones . Asymptotic behavior of solutions to difference equations involving ratios of elementary symmetric polynomials. In press, Journal of Difference Equations and Applications (2010), 15 pages.

[4] K. S. Berenhaut, and S. Stevic. The global attractivity of a higher order rational difference equation. J. Math. Anal. Appl. 326 (2007), no. 2, 940-944.

[5] P. S. Bullen, A dictionary of inequalities. Pitman Monographs and Surveys in Pure and Applied Mathematics, 97. Longman, Harlow, (1998).

[6] P. S. Bullen, Handbook of Means and their Inequalities, Mathematics and its Applications (Dordrecht), vol. 560. Kluwer Academic, Dordrecht (2003)

[7] R. DeVault, G. Ladas, and S. W. Schultz, On the recursive sequence $x_{n+1}=A / x_{n}+1 / x_{n-2}$. Proc. Amer. Math. Soc. 126 (1998), no. 11, 3257-3261.

[8] H. El-Metwally, E. A. Grove and G. Ladas, A global convergence result with applications to periodic solutions. J. Math. Anal. Appl. 245 (2000), no. 1, 161-170.

[9] H. El-Metwally, E. A. Grove, G. Ladas and H. D. Voulov, On the global attractivity and the periodic character of some difference equations. On the occasion of the 60th birthday of Calvin Ahlbrandt. J. Differ. Equations Appl. 7 (2001), no. 6, 837-850.

[10] M. El-Mik kawy and Tomohiro Sogabe, Notes on particular symmetric polynomials with applications. Appl. Math. Comput. 215 (2010), no. 9, 3311-3317.

[11] E. A. Grove and G. Ladas, Periodicities in Nonlinear Difference Equations, Chapman \& Hall/CRC Press, Boca Raton (2004).

[12] N. Kruse And T. Nesemann, Global asymptotic stability in some discrete dynamical systems. $J$. Math. Anal. Appl. 235 (1999), no. 1, 151-158.

[13] G. LadAs, Open problems and conjectures, J. Differential Equations Appl. 4, No. 3 (1998), 312.

[14] I. G. Macdonald, Symmetric functions and Hall polynomials. Second edition. With contributions by A. Zelevinsky. Oxford Mathematical Monographs. Oxford Science Publications. The Clarendon Press, Oxford University Press, New York, 1995.

[15] C. P. NiculesCU, A new look at Newton's inequalities. JIPAM. J. Inequal. Pure Appl. Math. 1 (2000), no. 2, Article 17, 14 pp. 
[16] C. P. Niculescu AND I. Rovenţa, The existence of a global attractor for a class of rational maps. Ann. Acad. Rom. Sci. Ser. Math. Appl. 1 (2009), no. 2, 215-227.

[17] H. Pollard And H. G. Diamond, The theory of algebraic numbers, 2nd ed., Carus Mathematical Monographs, Number 9, Mathematical Association of America, Washington, D. C., 1975.

[18] S. Rosset, Normalized symmetric functions, Newton's inequalities and a new set of stronger inequalities. Amer. Math. Monthly 96 (1989), no. 9, 815-819.

[19] S. Simic, A note on Newton's inequality. JIPAM. J. Inequal. Pure Appl. Math. 10 (2009), no. 2, Article 44, 4 pp.

[20] I. Stewart, Galois Theory. Third edition. Chapman \& Hall/CRC Mathematics. Chapman \& Hall/CRC, Boca Raton, FL, 2004.

[21] T. SUN AND H. XI, The periodic character of the difference equation $x_{n+1}=f\left(x_{n-l+1}, x_{n-2 k+1}\right)$, Advances in Difference Equations Volume 2008 (2008), Article ID 143723, 6 pages.

[22] Jianhong XU, Generalized $\lambda$-Newton inequalities revisited. JIPAM. J. Inequal. Pure Appl. Math. 10 (2009), no. 1, Article 19, 8 pp.

[23] X. YAnG, Global asymptotic stability in a class of generalized Putnam equations. J. Math. Anal. Appl. 322 (2006), no. 2, 693-698.

[24] X. YANG, F. SUN AND Y. TANG, A new part-metric-related inequality chain and an application. Discrete Dyn. Nat. Soc. 2008, Art. ID 193872, 7 pp.

[25] X. YANG, M. YANG AND H. LiU, A part-metric-related inequality chain and application to the stability analysis of difference equation. J. Inequal. Appl. 2007, Art. ID 19618, 9 pp. 